\title{
Successful transfer of day 10 horse embryos: influence of donor-recipient asynchrony on embryo development
}

\author{
Sandra Wilsher, Amber Clutton-Brock and W R Allen \\ The Paul Mellon Laboratory of Equine Reproduction, 3 Tower Stables, Cheveley Park, Newmarket, Suffolk CB8 9DE, \\ UK (formerly The Equine Fertility Unit, Newmarket, Suffolk, UK) \\ Correspondence should be addressed to SWilsher; Email: paulmellonlab@btconnect.com
}

\begin{abstract}
A total of 78 day 10 horse embryos were transferred non-surgically to recipient mares that had ovulated 9, 7, 6, 5, 4, 3, 2 or 1 day after (negative asynchrony), on the same day (synchronous), or 2 or 4 days before (positive asynchrony) the donor ( $n=6$ or 8 mares per group). Pregnancy rates between $100 \%(6 / 6)$ and $63 \%(5 / 8)$ were seen in recipient mares that were between +2 and -6 days asynchronous. Embryo survival to the heartbeat stage declined in recipients that were -7 days asynchronous and no embryos survived in recipients that were -9 days asynchronous. Irrespective of uterine asynchrony, cessation of embryo mobility and fixation at the base of a uterine horn occurred when the conceptus was $\sim 17$ days old. Conceptus growth and development was slowed when embryos were placed in negatively asynchronous uteri. At the greatest degree of negative asynchrony at which embryos survived to the heartbeat stage, i.e. -7 and -6 days, development of the embryo proper and allantois was retarded. Luteostasis was achieved in recipient mares when day 10 embryos were transferred to recipient mares at any stage of asynchrony between -9 and +2 days with respect to the donor. These results indicate that in the horse, there is a wide window for establishment of pregnancy following embryo transfer to asynchronous recipients. Although progesterone priming of the uterus to a stage equivalent to that of the transferred embryo does not appear to be a prerequisite for embryo survival, it does nonetheless influence embryonic development.

Reproduction (2010) 139 575-585
\end{abstract}

\section{Introduction}

It is a generally accepted tenet of equine embryo transfer that optimum pregnancy rates are achieved when transferring embryos to recipient mares that have ovulated 1 day before to 2 days after the donor (denoted as +1 to -2 days asynchrony: Allen 1982, Squires et al. 1982, McCue \& Troedsson 2003, Stout 2003, 2006). Work in other large animal species has shown that embryos placed in an asynchronous uterine environment may be exposed to inappropriate levels of growth factors, secreted proteins and steroid hormones so that the rate of embryonic growth and development is altered or embryonic death occurs (see Pope 1988, Barnes 2000 for reviews).

Current practice in commercial embryo transfer is to flush the uterus of a donor mare on day 7 or 8 after ovulation; flushing before this stage results in significantly lower embryo recovery rates (Boyle et al. 1989) due to the equine embryo's 6-day sojourn in the oviduct before it enters the uterine lumen between 156 and $168 \mathrm{~h}$ after ovulation (Battut et al. 1997, 2001). Older day 9 or 10 equine embryos have been widely considered too large and fragile to survive routine embryo transfer procedures. For example,
Squires et al. (1982) reported that more mares became pregnant following the transfer of day 8 embryos $(32 \%)$ than day 9 embryos (9\%). Similarly, Vogelsang et al. (1985) obtained no pregnancies following the transfer of day 9 or 10 embryos, compared to a $61 \%$ pregnancy rate following transfer of day 6 embryos, $55 \%$ from day 7 embryos and 25\% from day 8 embryos. Sirois et al. (1987) achieved no pregnancies when they transferred 4 day 10 horse embryos to recipients that were +1 to -1 days asynchronous with the donor, whereas Fleury et al. (1989) achieved a 69\% pregnancy rate when they transferred 16 day 9 horse embryos. In attempting to explain these variable results, Squires et al. (1985) suggested that the increased fluid volume-to-surface area ratio of days 9 and 10 embryos made them more prone to damage during the collection and transfer procedures. However, it must be borne in mind that all these earlier studies were undertaken before the technique of non-surgical embryo transfer had become widely used and operators had acquired much practical experience.

Transfer of day 10 embryos to asynchronous recipient mares could benefit the management of commercial equine transfer programmes and may provide a useful model for investigation of maternal influences on 
early embryogenesis. We reported recently on the successful transfer of day 10 horse embryos to -7 days asynchronous recipient mares (Wilsher \& Allen 2009), which clearly demonstrated an overriding influence of uterine environment on embryonic growth and early placentation. This paper extends that report and describes the rates of embryo survival following transfer of day 10 embryos to recipients that had ovulated from 9 days after to 4 days before the donor mares and discusses the implication of such asynchronous transfers on embryonic growth and conceptus development.

\section{Results}

\section{Embryo recovery}

Prior to the embryo flush carried out on day 10 , ultrasound scanning of the uterus revealed the presence of an embryo or embryos in $64 / 121(53 \%)$ of the donor mares; all these embryos measured $\geq 3 \mathrm{~mm}$ in diameter. In $5 / 121(4 \%)$ instances, the subsequent flushing of the mare's uterus produced an embryo $>3 \mathrm{~mm}$ diameter that had not been visualised ultrasonographically. In 3/121 (2\%) mares, an embryo of $>5 \mathrm{~mm}$ diameter was seen ultrasonographically but it proved impossible to recover that embryo despite repeated flushing of the uterus. (a)

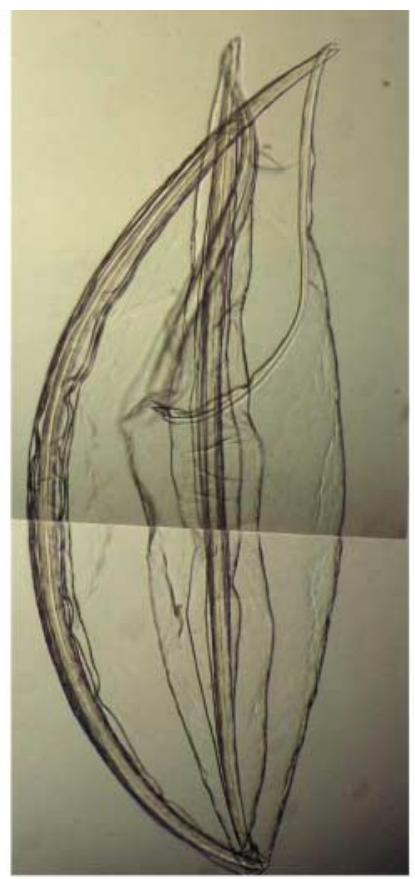

(b)

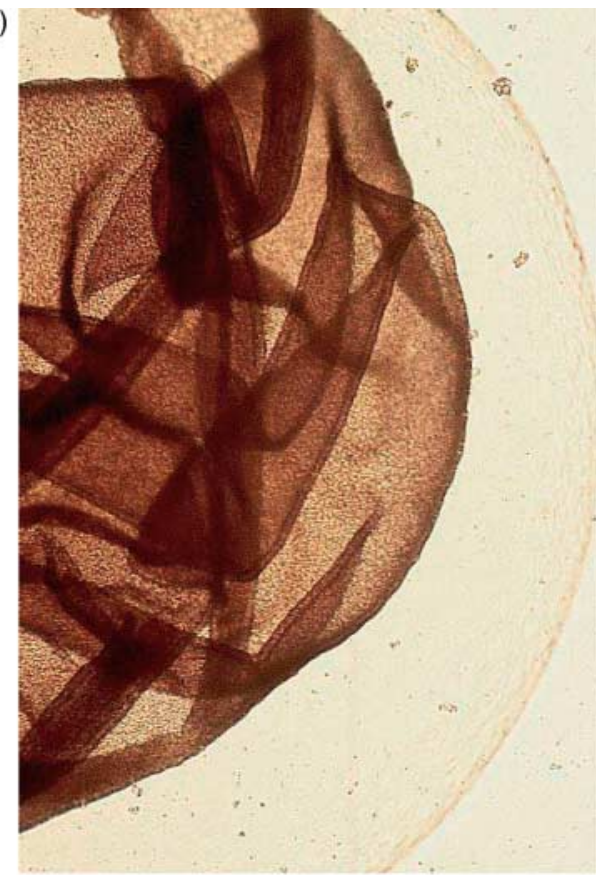

(c)

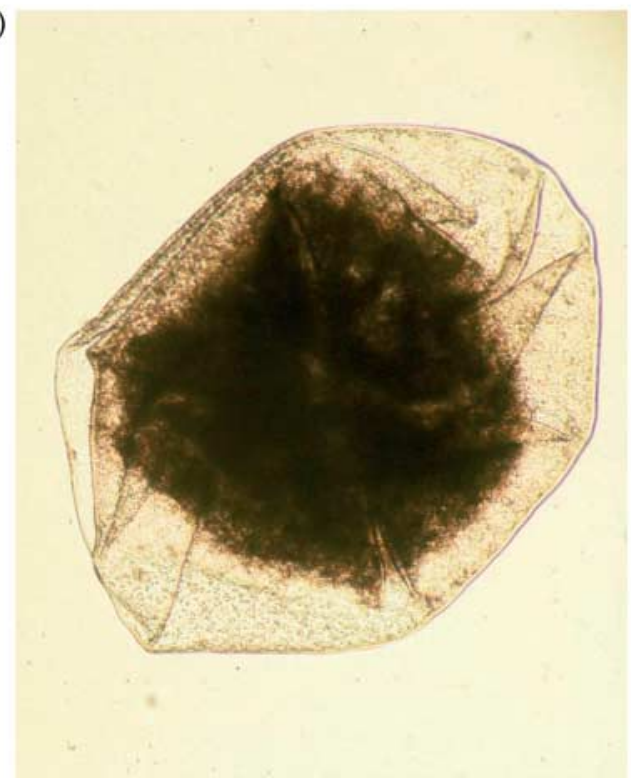

Figure 1 Examples of day 10 embryos recovered from donor mares. (a) Capsule material recovered from an embryo that was ruptured during the flushing procedure; (b) collapse of the trophoblast within an intact capsule of a day 10 embryo, damaged during flushing; (c) an abnormal, degenerating embryo, one of twins. The other embryo was normal and was transferred successfully. 
An embryo or embryos were recovered from 94/121 (78\%) flushes; two embryos were recovered from 16 of the flushes to yield a total of 110 embryos. Of these, 9/110 (8\%) were broken and either the capsule had ruptured (Fig. 1a) or the trophoblast had collapsed within the intact capsule (Fig. 1b); a further 6/110 (5\%) embryos were of poor quality (Fig. 1c). The 78 embryos that were transferred exhibited a mean diameter of $3.89 \pm 0.14 \mathrm{~mm}$ (range $1.80-7.00 \mathrm{~mm}$ ). All embryos, including multiple embryos from the same donor, were allocated randomly to the recipient mares.

\section{Embryo survival}

All inseminated control mares were diagnosed pregnant 12 days after ovulation $(9 / 9 ; 100 \%)$, and all went on to develop an embryo proper with a heartbeat (9/9; $100 \%)$. Pregnancy rates and conceptus viability, judged by an embryonic heartbeat, did not differ between the control mares and the synchronous transfers. The numbers of recipient mares in which a) an embryonic vesicle was present at the first ultrasound examination 2 days after transfer, b) a vesicle was still present at 10 days post transfer and c) a viable embryo with a heartbeat was seen ultrasonographically are detailed in Table 1. None of the embryos transferred to recipient mares with a -9 day asynchrony survived to the heartbeat stage, although anembryonic vesicles persisted until days 23-25 post transfer in two of these recipients. Similarly, three embryonic vesicles failed to develop an embryo proper in recipients with a -7 day asynchrony, and two more anembryonic vesicles were seen in recipients with an asynchrony of -4 and -2 days respectively.

Transfer of day 10 embryos to a uterine environment that was 2 days advanced resulted in survival of all six transferred embryos to the heartbeat stage.
In contrast, none of the six embryos transferred to recipient mares with a +4 day asynchrony survived. Nevertheless, three of these six were seen ultrasonographically 2 days after transfer despite obvious oedema in the endometrium and a serum progestagen level of $<1.0 \mathrm{ng} / \mathrm{ml}$ in these recipients; the vesicles had disappeared 2 days later.

Despite elevated serum progesterone concentrations, transient endometrial oedema was noted between days 16 and 18 after ovulation in three of the six +2 recipient mares. All six of the recipient mares with a +4 day asynchrony in which no embryos survived spontaneously returned to oestrus and, hence, showed significantly lower mean serum progesterone concentrations 2 and 4 days post transfer compared to all the other groups of recipient and control mares $(P<0.001)$. However, there were no differences in mean serum progesterone concentration profiles between the recipient mares in which the transferred embryos survived versus those in which the embryo failed $(P>0.05$ in all cases). Furthermore, mean progesterone concentration profiles did not differ between any group (recipient or control) in which a pregnancy was established $(P>0.05$ in all cases). Table 2 shows the mean \pm s.E.m. serum progesterone concentrations of the recipient mares on the day of embryo transfer and those of the control mares at day 10 of gestation. Recipient mares with a -9 day asynchrony had a significantly lower mean serum progesterone concentration on the day of transfer compared to all other groups $(P<0.05)$, with the exception of the -7 and +4 day asynchronous recipient groups.

Figure 2a shows the mean embryonic vesicle diameters of the control (non-transferred embryos derived from artificial insemination) and transferred embryos that survived until conceptus day 22 (recipient days 15-24), in relation to the level of asynchrony of the recipient

Table 1 Influence of donor-recipient asynchrony on pregnancy rates and early embryonic loss rates following transfer of day 10 embryos.

\begin{tabular}{|c|c|c|c|c|}
\hline \multirow[b]{2}{*}{$\begin{array}{l}\text { Degree of donor:recipient } \\
\text { asynchrony (days) }\end{array}$} & \multirow[b]{2}{*}{$\begin{array}{l}\text { Days after ovulation of the } \\
\text { recipient on day of ET }\end{array}$} & \multicolumn{3}{|c|}{ Number of recipient mares pregnant (\%) } \\
\hline & & 2 days post ET & 10 days post ET & With embryonic heartbeat \\
\hline+4 & 14 & $3 / 6(50 \%)$ & $0 / 6(0 \%)^{*}$ & $0 / 6(0 \%)^{*}$ \\
\hline+2 & 12 & $6 / 6(100 \%)$ & $6 / 6(100 \%)^{\dagger, \neq}$ & $6 / 6(100 \%)^{\dagger, \S}$ \\
\hline 0 & 10 & $6 / 6(100 \%)$ & $6 / 6(100 \%)^{t, \neq}$ & $6 / 6(100 \%)^{t, \S}$ \\
\hline-1 & 9 & $6 / 8(75 \%)$ & $5 / 8(63 \%)^{*, t, \neq}$ & $5 / 8(63 \%)^{*},+, \S$ \\
\hline-2 & 8 & $6 / 8(75 \%)$ & $6 / 8(75 \%)^{\dagger, \neq}$ & $5 / 8(63 \%)^{*,+, \S}$ \\
\hline-3 & 7 & $6 / 8(75 \%)$ & $6 / 8(75 \%)^{\dagger, \neq}$ & $6 / 8(75 \%)^{\dagger, \ddagger, \S}$ \\
\hline-4 & 6 & $8 / 8(100 \%)$ & $8 / 8(100 \%)^{\dagger, \neq}$ & $7 / 8(83 \%)^{\dagger, \ddagger, \S}$ \\
\hline-5 & 5 & $6 / 8(75 \%)$ & $6 / 8(75 \%)^{t, \neq}$ & $6 / 8(75 \%)^{\dagger, \ddagger, \S}$ \\
\hline-6 & 4 & $5 / 6(83 \%)$ & $5 / 6(83 \%)^{\dagger, \neq}$ & $5 / 6(83 \%)^{\dagger, \neq, \S}$ \\
\hline$-7^{\mathrm{a}}$ & 3 & $8 / 8(100 \%)$ & $6 / 8(75 \%)^{\dagger, \neq}$ & $3 / 8(38 \%)^{*,+, \neq}$ \\
\hline-9 & 1 & $4 / 6(67 \%)$ & $2 / 6(33 \%)^{*,+}$ & $0 / 6(0 \%)^{*}$ \\
\hline Control & $\begin{array}{l}\text { Al derived, non-ET } \\
\text { pregnancies }\end{array}$ & 9/9 (100\%) & $9 / 9(100 \%)^{\ddagger}$ & $9 / 9(100 \%)^{\S}$ \\
\hline
\end{tabular}

$*_{*,+, \neq, \S}$ Values with different superscripts within a column are significantly different at $P<0.05$.

${ }^{a} \mathrm{~A}$ full description of these transfers and the subsequent embryonic growth was reported by Wilsher \& Allen (2009). 


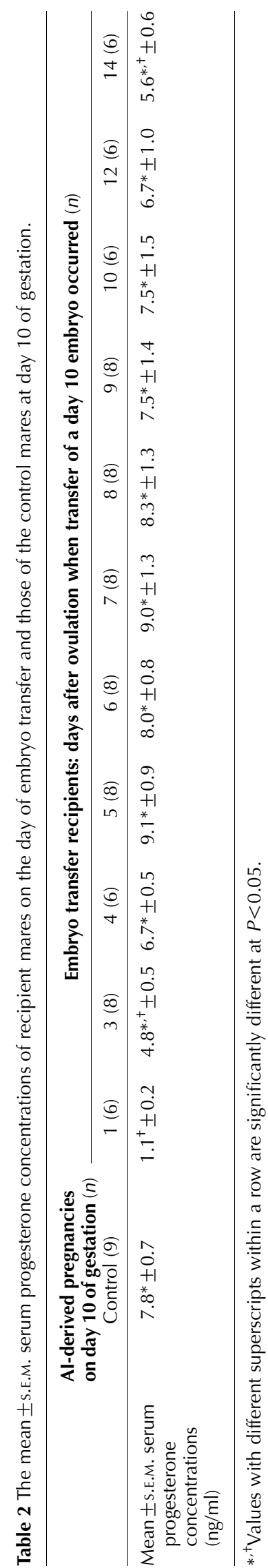

mare, while Fig. $2 \mathrm{~b}$ shows the same data plotted in relation to embryonic age. Most groups showed a typical growth profile for an equine embryo; namely, exponential expansion of the vesicle between days 10 and 16 followed by a plateau in growth after this time. However, the embryos in both the -7 and -6 days asynchronous recipient groups continued to expand beyond conceptus day 18 (recipient day 11 or 12 ). Although the control embryos showed the lowest mean vesicle diameter between days 18 and 22, vesicle diameter did not differ significantly from the diameters of embryos transferred to recipient mares that had ovulated between 5 days before $(-)$ and 2 days after $(+)$ the donor $(P>0.05)$. The mean diameters of embryos on days 2, 4 and 6 after transfer were significantly lower in recipient mares with a
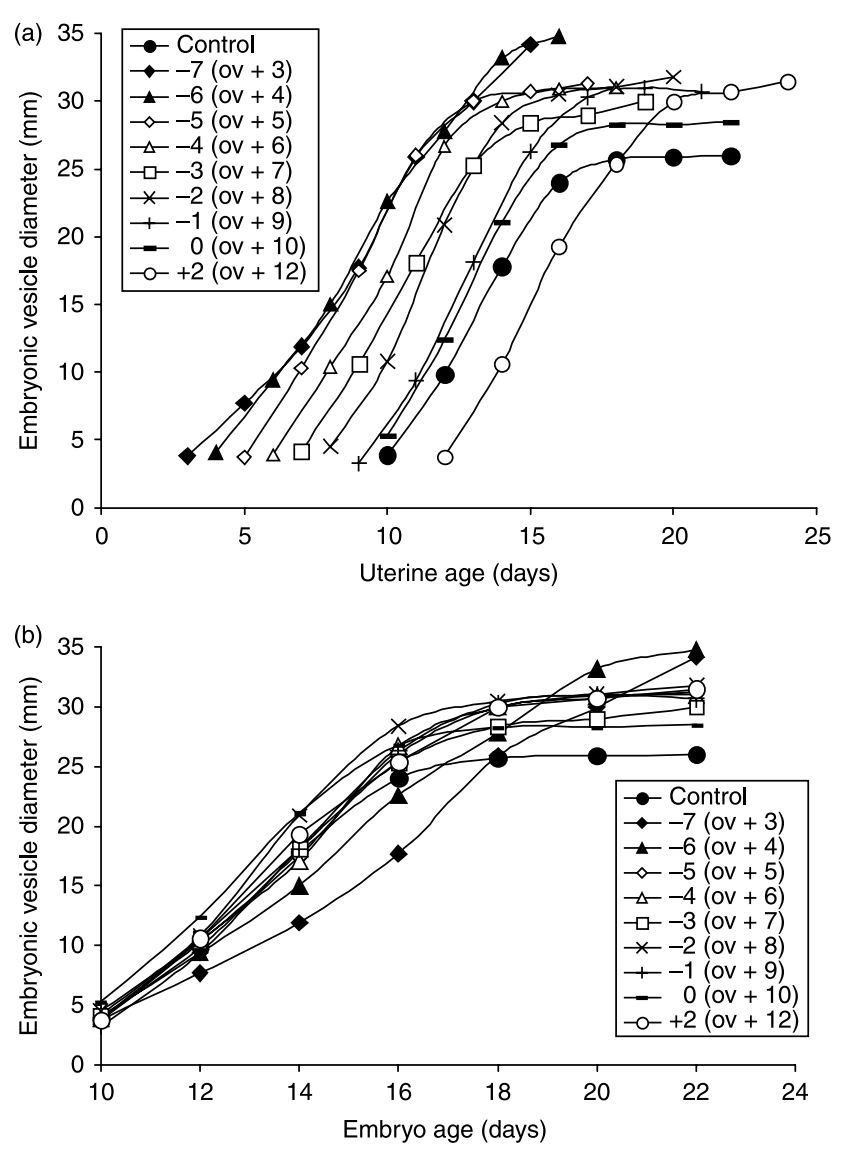

Figure 2 Embryonic vesicle diameters of transferred and control embryos. (a) The mean embryonic vesicle diameters of the nontransferred control and transferred embryos that survived until day 22 (control, $n=9 ;-4$ day asynchrony, $n=7 ;+2,0,-3$ and -5 asynchrony, $n=6 ;-1,-2$ and -6 day asynchrony, $n=5 ;-7$ day asynchrony, $n=3$; anembryonic vesicles are not included) in relation to the level of asynchrony of the recipient mare; (b) mean embryonic vesicle diameter in relation to embryonic age. The S.E.M. of mean vesicle diameters ranged from 0.3 to 3.2. The diameters of transferred embryos on day 10 were obtained from in vitro measurement prior to transfer. All other values were derived from ultrasound measurements made in vivo in the recipient or control mares. 
Donor-recipient asynchrony
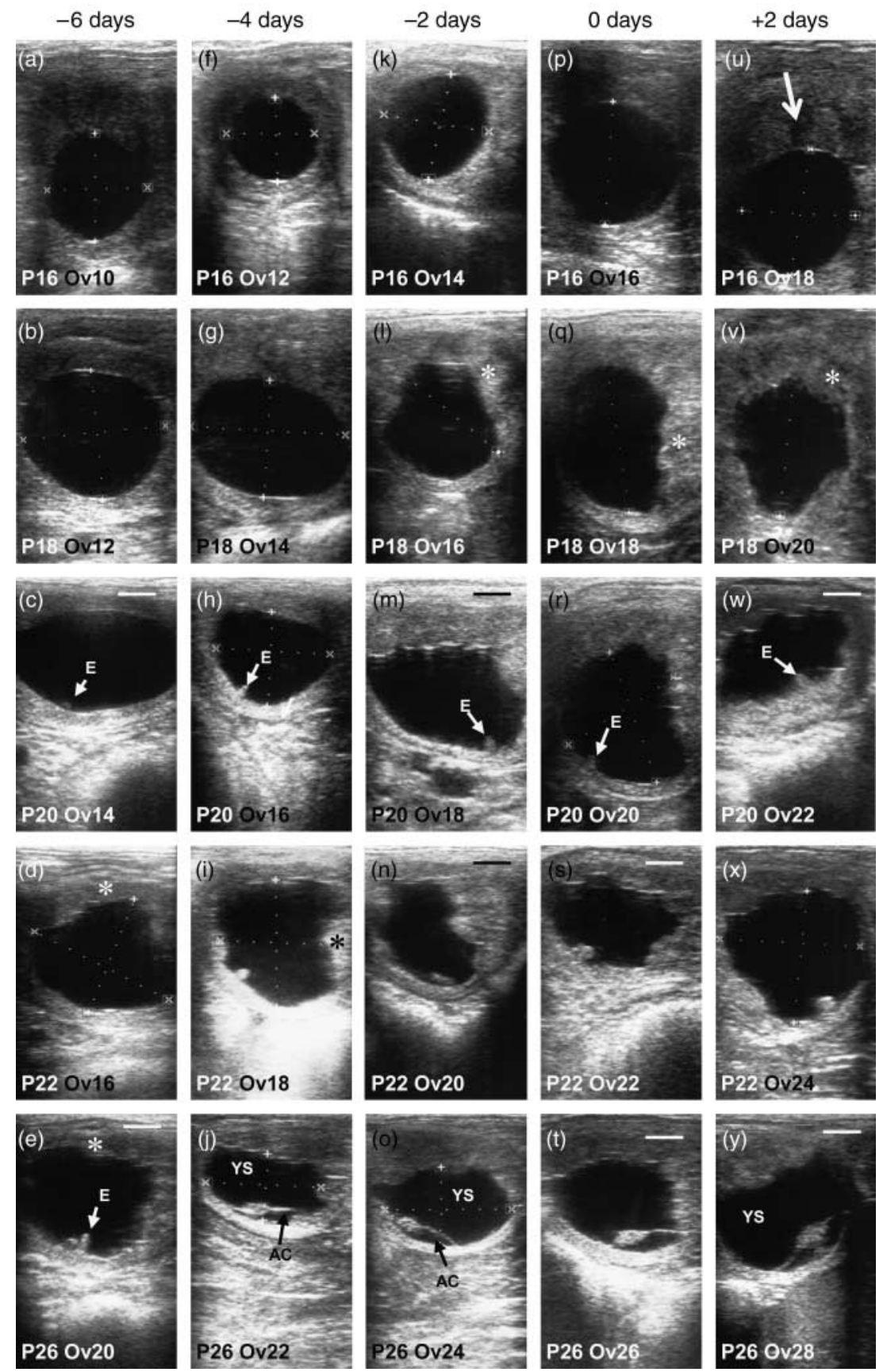

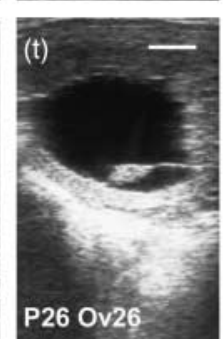

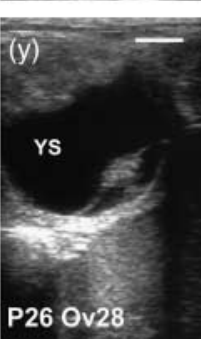

Figure 3 Development between 6 and 16 days post transfer of day 10 embryos transferred to the uteri of recipient mares with asynchronies of -6 $(\mathrm{a}-\mathrm{e}),-4(\mathrm{f}-\mathrm{j}),-2(\mathrm{k}-\mathrm{o}), 0(\mathrm{p}-\mathrm{t})$ and +2 days $(\mathrm{u}-\mathrm{y})$. Note the uterine oedema (arrowed) at day 18 after ovulation in the recipient with a +2 day asynchrony $(\mathrm{u})$. In those recipients with a negative asynchrony thickening of the mesometrial quadrant of the endometrium (asterisk) and the resulting loss of the spherical outline occurs at a progressively later embryo age but a similar uterine age. Note also the delayed appearance of the embryo $(\mathrm{E})$ and allantois in the conceptus transferred to the -6 day asynchronous recipient (e) compared to the other embryos at day 16 post transfer in which the expanding allantois can be seen as an echogenic line separating the regressing yolk sac and the expanding allantoic cavity (AC; j, o, t and y). P, embryo age; Ov, days post ovulation of recipient. Caliper dots on any line are $0.5 \mathrm{~cm}$ apart; scale bar $=1 \mathrm{~cm}$.
-7 day asynchrony compared to all other groups with an asynchrony of -5 days or less $(P \leq 0.01)$. Despite the initial slowing in growth rate in embryos transferred to uteri with a -7 or -6 day asynchrony, expansion continued so that by 12 days post transfer they showed a significantly greater mean diameter than either the control or the synchronously transferred embryos $(P \leq 0.01$, in both cases).

\section{Conceptus development}

Figure 3 illustrates conceptus development, as viewed ultrasonographically, of day 10 embryos transferred to recipient mares with varying degrees of asynchrony. Table 3 shows the mean \pm s.E.M. day for recognisable events associated with early development in embryos transferred to recipient mares at varying stages of asynchrony, compared to control pregnancies. 
Table 3 Influence of donor-recipient asynchrony on embryo fixation, endometrial thickening and the appearance of a heartbeat in transferred day 10 embryos.

\begin{tabular}{|c|c|c|c|c|}
\hline \multirow[b]{2}{*}{ Mare groups } & \multirow[b]{2}{*}{ Number of mares ${ }^{b}$} & \multicolumn{3}{|c|}{ First detection (mean embryonic age in days \pm s.E.M. $)^{a}$} \\
\hline & & Embryo fixation $^{\mathrm{c}}$ & $\begin{array}{l}\text { Loss of spherical shape plus } \\
\text { endometrial thickening }\end{array}$ & Appearance of a heartbeat \\
\hline \multicolumn{5}{|c|}{ Degree of asynchrony donor:recipient (days) } \\
\hline+2 & 6 & $17.7 \pm 0.33$ & $18.7 \pm 0.42 *$ & $21.3 \pm 0.42 *$ \\
\hline 0 & 6 & $17.3 \pm 0.42$ & $18.3 \pm 0.33^{*}$ & $21.3 \pm 0.42 *$ \\
\hline-1 & 5 & $17.6 \pm 0.40$ & $19.6 \pm 0.75^{*,+}$ & $22.8 \pm 0.49^{*,+}$ \\
\hline-2 & 5 & $17.6 \pm 0.40$ & $19.6 \pm 0.52^{*,+}$ & $22.4 \pm 0.89^{*,+}$ \\
\hline-3 & 6 & $17.3 \pm 0.42$ & $20.0+0.52^{*,+, \neq}$ & $23.0 \pm 0.45^{*,+}$ \\
\hline-4 & 7 & $17.7 \pm 0.29$ & $21.4 \pm 0.37^{\dagger, \neq}$ & $23.7 \pm 0.29^{*,+}$ \\
\hline-5 & 6 & $16.7 \pm 0.42$ & $22.3 \pm 0.33^{\ddagger}$ & $25.0 \pm 0.45^{+, \neq}$ \\
\hline-6 & 5 & $17.2+0.49$ & $23.6+0.75^{\ddagger}$ & $28.8+0.67^{\S}$ \\
\hline-7 & 3 & $17.3 \pm 0.67$ & $22.7 \pm 0.67^{\ddagger}$ & $27.3 \pm 0.67^{\ddagger, \S}$ \\
\hline Control & 9 & $17.1 \pm 0.35$ & $19.1 \pm 0.35^{*}$ & $21.6 \pm 0.29 *$ \\
\hline
\end{tabular}

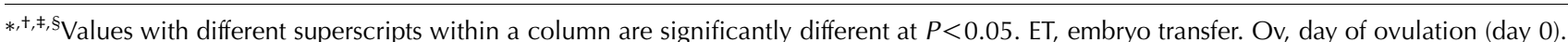

${ }^{a}$ Ultrasound examinations were performed only on alternate days and, hence, observations recorded on any single day could be subject to an error of \pm 1 day. ${ }^{b}$ The number of mares in which the embryo survived until the heartbeat stage; anembryonic vesicles are not included. ${ }^{C}$ Embryo fixation was defined as the first day that the vesicle was located at the base of the uterine horn and noted to be in the same location on all subsequent examinations.

Uterine-embryo asynchrony did not affect the age at which the embryo became fixed at the base of one of the uterine horns $(P=0.887)$. However, with increasing negative asynchrony, the mean conceptus age at which disproportionate thickening of the endometrial folds in the mesometrial quadrant of the uterus was noted, and the conceptus age when an embryo with a discernable heartbeat first appeared, increased such that both events occurred at a significantly advanced age in embryos transferred to uteri with a $\geq-5$ day asynchrony compared both to recipients with an asynchrony of -2 to +2 days and control, inseminated mares $(P \leq 0.001$, in all cases; Table 3$)$. No enhancement of embryonic growth occurred in embryos transferred to an advanced uterine environment ( +2 day asynchrony).

Development of the five surviving embryos transferred to recipient mares with a -6 day asynchrony is illustrated in Figs 3a-e and 4e-t. As previously reported for the day 10 embryos transferred to -7 day asynchronous uteri (Wilsher \& Allen 2009), embryos transferred to uteri with an asynchrony of -6 days showed significantly delayed development compared to Al-derived or synchronously transferred embryos. For example, the tiny echogenic spot believed to represent the embryo proper was often noted in the ventral quadrant of the vesicle between conceptus days 20 and 24 (recipient days 14 and 18), but this was not seen again until the appearance of a much larger embryo more than 4 days later (Figs 3c-e and $4 \mathrm{f}-\mathrm{h}, \mathrm{j}-\mathrm{I}$ and $\mathrm{m}-\mathrm{p}$ ). This was coupled with a delayed appearance, and then with rapid expansion, of the allantois between conceptus days 28 and 32 (recipient days 22 and 26). This phenomenon was exemplified in two of these mares in which, despite careful ultrasonographic examinations, an embryo proper could not be seen within the vesicle on conceptus day 28 (recipient day 22) yet, 4 days later, a visible embryo with a beating heart and an expanding allantois was visualised (Fig. $4 \mathrm{k}-\mathrm{I}$ and $\mathrm{o}-\mathrm{p}$ ).

\section{Discussion}

In conventional embryo transfer programmes, horse embryos are usually transferred to recipient mares that have ovulated 1 day before to 3 days after the donor. When the recipient mare has ovulated $\geq 2$ days ahead of the donor, pregnancy rates are reduced (Allen 1982, Squires et al. 1982, McCue \& Troedsson 2003, Stout 2003, 2006) and early pregnancy losses are increased (Carnevale et al. 2000). Two major reasons are put forward for this decline in pregnancy rate following transfer to recipients that ovulate ahead of the donor. First, the uterine environment changes under the dominance of progesterone (Zavy et al. 1982, Hinrichs et al. 1989), so that an embryo transferred to a positively asynchronous uterus may be exposed to an inappropriate environment (Barnes 2000). Secondly, it is believed that the equine blastocyst must transmit its antiluteolytic maternal recognition of pregnancy signal before day 10 after ovulation if it is to suppress the upregulation of oxytocin receptors and prevent luteolysis (Goff et al. 1987, Stout et al. 1999, 2000). Evidence from cattle suggests that it is difficult to inhibit upregulation of oxytocin receptors once the process has commenced (Gilbert et al. 1989). Furthermore, recipient mares that ovulate 2 or 3 days ahead of the donor do not maintain the pregnancy even if their return to oestrus is prevented by the administration of exogenous progesterone (Clarke et al. 1987, Pool et al. 1987) with pregnancy failure presumably resulting from the advanced uterine 



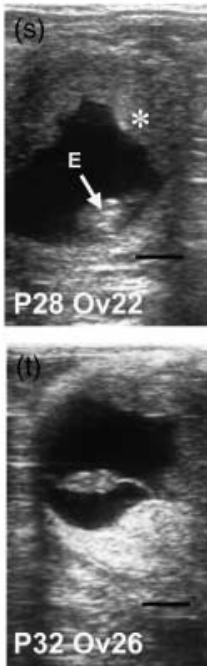

Figure 4 Conceptus development between days 20 and 32 of gestation in a pregnancy achieved by artificial insemination (a-d) compared with that of day 10 embryos transferred to four different recipient mares with a -6 day asynchrony $(\mathrm{e}-\mathrm{h}, \mathrm{i}-\mathrm{l}, \mathrm{m}-\mathrm{p}$ and $\mathrm{q}-\mathrm{t})$. Note the tiny echogenic spot denoting the embryo (E) in Mare BB (f), Mare HM (j) and Mare $\mathrm{LaC}(\mathrm{m})$ and its slow development compared to the control pregnancy (a-d). At 32 days of gestation, the control conceptus shows enlargement of the allantoic cavity (AC) and regression of the yolk sac (rYS) such that the former represents over half of the conceptus (d).

By comparison, in the recipient mares carrying the asynchronously transferred embryos the allantoic cavity (AC) occupied less than a third of the conceptus ( $h, \mathrm{l}, \mathrm{p}$ and $\mathrm{t}$ ). P, embryo age; Ov, days post ovulation in the recipient or control mare. Caliper dots on any line are $0.5 \mathrm{~cm}$ apart; scale bar $=1 \mathrm{~cm}$. environment in which the embryo finds itself. However, our findings that all the day 10 embryos transferred to recipient mares that were either 10 or 12 days post ovulation ( 0 or +2 day asynchrony) survived suggests the former dogma should be re-evaluated since the luteolytic cascade is either stoppable once initiated on day 10 or, more likely, the cascade does not actually begin until after day 12 post ovulation. By day 14 post ovulation, the luteolytic cascade in the mare has clearly commenced and cannot be halted since all six recipients at this stage into which a day 10 embryo was transferred spontaneously returned to oestrus, even in those mares in which an embryonic vesicle was still ultrasonographically visible.

At the negative end of the window of asynchrony investigated in the present experiment, day 10 embryos transferred to recipients with an asynchrony of up to -9 days suppressed luteolysis. This occurred regardless of the developmental competence of the conceptus, both in terms of its complete lack of development (i.e. an anembryonic or trophoblastic vesicle) or delayed development of the embryo and membranes. The ability of trophoblastic vesicles to suppress cyclicity was not unexpected since Ball et al. (1989) had reported luteal maintenance following the transfer of trophoblastic vesicles to day 10 recipients. Although the delayed development of the embryo and membranes in the present experiment could have resulted in the luteostatic signal being delayed, it was nonetheless surprising to find that at the time when maternal recognition of pregnancy is assumed to occur (i.e. days 10-16 in the recipient mare) the transferred conceptus, although retarded was, in some instances, 19-25 days old. Furthermore, although previous work has suggested that uterine migration of the embryo until the time of fixation is essential for prevent luteolysis (McDowell et al. 1988, Griffin \& Ginther 1993), all of the transferred embryos became fixed when they were $\sim 17$ days old regardless of the degree of donor-recipient asynchrony. Hence, embryo movement ceased in some recipients when the uterus was only 9 days 
old yet luteostasis still occurred. In a similar vein, Rivera del Alamo et al. (2008) demonstrated that the insertion of a relatively immobile $20 \mathrm{~mm}$ water-filled plastic ball into the uterine lumen of cycling mares 2-4 days after ovulation prolonged luteal function in 9 of 12 treated animals, suggesting embryo mobility may not be essential for prolongation of luteal function.

Although uterine tone has also been associated with conceptus fixation (Feo 1980, Ginther 1983a, Griffin \& Ginther 1991, Carnevale \& Ginther 1992), and no doubt plays a role, intraluminal impediment, with or without increased uterine tone, would appear to be the overriding influence on fixation time since mobility of the transferred embryos ceased at the same conceptus age regardless of the stage of the uterus. This accords with previous work that demonstrated that fixation occurs earlier for larger embryos (Gastal et al. 1996). In recipient mares with the greatest degree of asynchrony in which embryos survived (i.e. -6 and -7 days with respect to the donor), the embryos continued to increase in diameter after fixation around embryo day 17 (recipient day 10 or 11). Turgidity of the normal pregnant uterus increases steadily from day 10 or 11 after ovulation until day 16 (Bonafas et al. 1994), when the now intense uterine tone is believed to be responsible for the plateau in conceptus diameter that occurs between approximately days 16 and 26 (Ginther 1998). Hence, the reduced uterine tone in the day 10 or 11 recipient uteri could have allowed the day 17 conceptus to continue to remain spherical and expand until uterine tone increased. The delay in uterine tone in relation to conceptus age was further exemplified by the later occurrence of endometrial thickening in the mesometrial quadrant and the loss of a spherical outline seen in the transferred conceptuses with the greatest degree of donor-recipient asynchrony.

Under conditions of embryo-uterus asynchrony in other animal species, a variety of complications can occur, including failure of the embryo to implant, early embryonic mortality or retarded or accelerated growth (see Pope 1988, Barnes 2000 for reviews). For example, sheep embryos transferred to a more advanced uterus increase their rate of cell division (Wilmut et al. 1985) and slow this rate when transferred to a less advanced uterus (Wilmut \& Sales 1981, Lawson et al. 1983, Wilmut et al. 1986). In the present experiment, an advanced uterine environment in the mare was not associated with any observable enhancement in embryonic development although, as previously observed in the sheep, embryonic development was modified when embryos were exposed to a retarded uterine environment and was fatally modified in $63 \%$ of the embryos transferred to -7 days asynchronous uteri and $100 \%$ of embryos transferred to uteri that were -9 days asynchronous.

The observed delay in the development of the embryo proper and the allantois in the pregnancies at the greatest degree of negative asynchrony is difficult to explain.
In equids, in the normal course of events, the allantois first appears around days 20-21 after ovulation (van Niekerk \& Allen 1975, Latshaw 1987), as an evagination from the hindgut of the embryo. Its emergence is critical for the establishment of the chorioallantoic placenta, and it plays a vital role in vasularising the chorion. Furthermore, failures in the development of the allantois have been cited as a potential cause of embryonic loss in both sheep (Robinson 1951) and cattle (Peterson et al. 2000). In ruminant species, a temporal expression of genes associated with the emergence of the allantois has been identified (Ledgard et al. 2006), and it is likely that a similar stage-dependent regulation of embryonic development occurs in the horse. The role of maternal environment in this regulation is not fully understood, although in mammals that alter their gestation length by employing embryonic diapause, it is uterine factors that induce and maintain the embryo in its developmental arrest. Suppression of cell proliferation at the blastocyst stage occurs in most of the species that undergo diapause but the bat is a notable exception to this general rule in which variations in the rate of later embryonic development have been noted (Rasweiler \& Badwaik 1997). Ultrasonographically, this appeared to be the case in the affected mares in the present experiment.

It is unclear whether embryonic diapause is due to the absence of uterine factors necessary for the development of the blastocyst or whether the uterus actively maintains diapause by inhibition of development (see Lopes et al. 2004 for review). Support for the former view can be found in studies that have shown increases in protein synthesis and secretion coinciding with the termination of diapause in roe deer (Lambert et al. 2001) and carnivores (Mead 1989). In the mare, it is known that uterine secretions vary in a stage-dependent manner related to the duration of either endogenous or exogenous progesterone (Zavy et al. 1982, Hinrichs et al. 1989), and it is reasonable to assume that some of these proteins play a role in promoting embryonic development, particularly in view of the increased incidence of early pregnancy failure in older mares suffering fibrotic degenerative changes in the endometrium, which render the secretory glands non-functional (Stewart et al. 1998, Morris \& Allen 2002, Allen et al. 2007). The failure of all the day 10 embryos transferred to day 1 uteri to develop an embryo proper, only $3 / 8$ transferred to a day 3 uterus to do so, and the slowed development of $5 / 6$ of the embryos placed in a day 4 uterus strongly suggests the development of stagedependent factors in the uterine environment, which allow embryonic development to proceed. Furthermore, the mean serum progesterone level in the day 3 or 4 uterus on the day of transfer did not differ significantly, suggesting that the level of progesterone when the day 10 embryo entered the recipient mare's uterus was not the overriding factor determining embryo survival. 
From a practical aspect, the embryo flushing equipment used in the present experiment would need to be modified before being used in a commercial setting. Although overall embryo recovery rate was equivalent to that achieved in embryo transfer programmes using fresh semen from fertile stallions (Losinno et al. 2001), both the failure to recover some ultrasonographically visualised embryos and the damage suffered by $8 \%$ of the embryos that were recovered would not be acceptable in a commercial programme. Embryonic damage in all likelihood occurred at the two points in the flushing system that provided the greatest impediment to the passage of the embryo; namely, the entry/exit holes in the flushing catheter and the internal diameter of the entry port into the embryo filter. Although this small percentage of embryos did suffer damage, the fact that so many passed unscathed through the narrow openings is a testament to the protective strength provided by the glycoprotein equine capsule (Betteridge 1989, Oriol et al. 1993a, 1993b). This is not surprising when one considers that the embryo is subjected to strong myometrial contractions during its movement throughout the uterus between days 6 and 17 after ovulation (Ginther 1983b, Allen \& Bracher 1992) to the extent that the day 13 or 14 embryo may undergo periodic compressions every 5-14 s with the resilience and elasticity of the capsule allowing temporary distortion of the spherical embryonic yolk sac (Ginther 1985).

One further problematic aspect of the transfer of large day 10 embryos is the use of transfer pipettes with an internal diameter $\geq 5 \mathrm{~mm}$; the capillary forces required to hold the embryo in its transfer medium in set columns within the pipette do not come into play in these larger bore pipettes. Nevertheless, transfer was successfully accomplished and a high rate of pregnancies resulted despite the perilous movement of the fluid columns within the pipette during the transfer procedure.

In conclusion, these results show clearly that a day 10 embryo can survive and develop, to at least the heartbeat stage, in a uterus that is as much as 7 days behind or 2 days ahead in developmental terms. Since conceptus growth and development was delayed when embryos were placed in less advanced uteri, it can be concluded that although progesterone priming of the uterus to a stage equivalent to that of the transferred embryo is not a prerequisite for embryo survival, it does nonetheless influence embryonic development.

\section{Materials and Methods \\ Management of the mares}

The use of the animals was in accordance with the UK Animal (Scientific Procedures) Act (1986). Follicular development and ovulation in experimental donor, recipient and control Thoroughbred mares, aged 3-12 years, was monitored by daily ultrasound scanning of their ovaries during oestrus combined with daily measurement of serum progesterone concentrations (Allen \& Sanderson 1987). The donor and control mares were inseminated once with $300-500 \times 10^{6}$ freshly collected, extended, stallion spermatozoa when they exhibited a dominant ovarian follicle of $\geq 35 \mathrm{~mm}$ diameter. Coincidentally, an i.m. injection of $0.75 \mathrm{mg}$ of the GNRH analogue, deslorelin (BET Pharm Laboratories, Kentucky, KY, USA), was administered to induce ovulation of the maturing follicle 40-42 h later (Fleury et al. 2004). Recipient mares underwent the same procedures but were not inseminated. For all mares, the day when ovulation was detected was classified as day 0 of pregnancy or the oestrous cycle.

\section{Embryo recovery}

On day 10 after ovulation, the uterus of each control and donor mare was scanned using a $7.5 \mathrm{MHz}$ transrectal probe attached to a Honda HS-2000VET (BCF Technology, Livingston, Scotland) ultrasound scanner to establish if a conceptus could be observed ultrasonographically. If seen, its diameter was measured using the calliper function within the ultrasound machine. Regardless of the outcome of this ultrasound examination, the uterus of each donor mare was then flushed twice with $500-2000 \mathrm{ml}$ of a commercial embryo transfer flushing medium (Emcare Complete; ICPbio Ltd, Auckland, New Zealand) using a standard two-way $100 \mathrm{~cm}$, silicone, 28 French gauge embryo flushing catheter (Stallion Foley Catheter; SurgiVet, Waukesha, WI, USA) and a commercial embryo filter (Sure Flush Filter; Professional Embryo Transfer Supply, Inc., Canton, TX, USA). The flushing medium was recovered by gravity flow alone in the first instance, and recovery was assisted by the i.v. administration of 20 i.u. of oxytocin (Intervet UK Ltd, Milton Keynes, Bucks, UK) to induce myometrial contractions after the second flush was undertaken. Recovered embryos were graded morphologically using the scale proposed by McKinnon \& Squires (1988), and their diameters were measured using a stage graticule. They were then placed in a holding and transfer medium (Emcare Hold; ICPbio Ltd) and transferred within $1 \mathrm{~h}$ of collection.

\section{Embryo transfer}

A total of 78 Grade I day 10 embryos were transferred nonsurgically to individuals in 11 groups of recipient mares that had ovulated 9, 7, 6, 5, 4, 3, 2 or 1 day after (-) the donor, on the same day (0) as the donor, or 2 or 4 days before $(+)$ the donor ( $n=6$ or 8 mares per group). The embryos were transferred using a commercial, $63.5 \mathrm{~cm}$, insemination pipette (Reproduction Resources, Walworth, WI, USA) or a rigid plastic tube made from the protective plastic sheath around either an oocyte-pick-up needle or an endometrial swab to which a small piece of silicone tube and a syringe adapter were fitted. For each transfer, the smallest diameter tube into which the embryo would fit comfortably was selected. Non-surgical transfer was performed using the method described by Wilsher \& Allen (2004) in which a Polansky speculum is inserted into 
the vagina to allow visualisation of the cervix, prior to its retraction using modified forceps. The pipette containing the embryo is then passed through the straightened cervix and the embryo deposited in the uterine lumen.

\section{Pregnancy diagnosis and monitoring conceptus growth}

Two days after embryo transfer to the recipient mares, or 12 days after ovulation in the control mares, pregnancy diagnosis was performed by transrectal ultrasound of the uterus. These examinations were then repeated on alternate days to measure the size of the vesicle and the degree of development of the embryo. They continued until a viable embryo with a visible heartbeat was seen, or until embryonic death had occurred, when most of the mares received an i.m injection of $250 \mu \mathrm{g}$ cloprostenol (Estrumate; Schering-Plough, Middlesex, UK) to induce luteolysis and a return to oestrus.

\section{Hormone measurements}

Jugular vein blood samples were recovered daily from all recipient or control mares from the day of ovulation until day 10 and thereafter on alternate days until termination of the pregnancy or a return to oestrus. The serum was decanted after centrifugation and assayed for progesterone concentrations using the enzyme-linked immunoassay (AELIA) described by Allen \& Sanderson (1987), who recorded its sensitivity as $0.135 \mathrm{ng} / \mathrm{ml}$ and found its precision to be described by intraand inter-coefficients of variation of 6 and $8 \%$ respectively.

\section{Statistical analysis}

All statistical analyses were performed using a computer software package (SigmaStat v.2.03; SPSS Inc., Chicago, IL, USA). The $\chi^{2}$ test was employed to determine if there was an effect of asynchrony on pregnancy rates in the recipient mares and, if significant, multiple comparisons were made comparing each asynchronous transfer group individually. One-way ANOVA followed by Tukey's test was used to determine differences in embryonic vesicle growth at different stages of development and to compare serum progesterone concentrations on the day of embryo transfer. Statistical significance was set at $P \leq 0.05$. In addition, one-way RM ANOVA was used to determine if progesterone concentrations in the mares' blood affected the likelihood of survival of a transferred embryo.

\section{Declaration of interest}

The authors declare that there is no conflict of interest that could be perceived as prejudicing the impartiality of the research reported.

\section{Funding}

This study was kindly supported by the Horseracing Betting Levy Board and the Childwick Trust.

\section{Acknowledgements}

The authors are grateful to Miss Michaela Kölling, Dr Jenny Ousey and Mrs Michelle Wright for kind assistance with the preparation and handling of donor and recipient mares.

\section{References}

Allen WR 1982 Embryo transfer in the horse. In Mammalian Egg Transfer, pp 33-48. Ed. CE Adams. Boca Raton, FL: CRC Press.

Allen WR \& Bracher V 1992 Videoendoscopic evaluation of the mare's uterus. III. Findings in the pregnant mare. Equine Veterinary Journal 24 285-291.

Allen WR \& Sanderson MW 1987 The value of a rapid progesterone assay (AELIA) in equine stud veterinary medicine and management. In Proceedings of the 9th Bain-Fallon Memorial Lectures, pp 75-82. Sydney: AEVA.

Allen WR, Brown L, Wright M \& Wilsher S 2007 Reproductive efficiency of Flatrace and National Hunt mares and stallions in England. Equine Veterinary Journal 39 438-445.

Ball BA, Altschul M \& Hillman RB 1989 Luteal maintenance in mares after transfer of equine trophoblastic vesicles. Equine Veterinary Journal Supplement 8 21-24.

Barnes FL 2000 The effects of the early uterine environment on the subsequent development of the embryo and fetus. Theriogenology 53 649-658.

Battut I, Colchen S, Fieni F, Tainturier D \& Bruyas JF 1997 Success rates when attempting to non-surgically collect equine embryos at 144,156 and 168 hours after ovulation. Equine Veterinary Journal 25 60-62.

Battut I, Grandchamp des Raux A, Nicaise JL, Fieni F, Tanturier D \& Bruyas JF 2001 When do equine embryos enter the uterine cavity? An attempt to answer. In Proceedings of the 5th International Symposium on Equine Embryo Transfer, Havemeyer Foundation Monograph Series 3, pp 60-61. Eds T Katila \& JF Wade. Newmarket, UK: R\&W Publications.

Betteridge KJ 1989 The structure and function of the equine capsule in relation to embryo manipulation and transfer. Equine Veterinary Journal Supplement 8 92-100.

Bonafas LD, Carnevale EM, Smith CA \& Ginther OJ 1994 Development of uterine tone in nonbred and pregnant mares. Theriogenology $\mathbf{4 2}$ 1247-1255.

Boyle MS, Sanderson MW, Skidmore J \& Allen WR 1989 Use of serial progesterone measurements to assess cycle length, time of ovulation and timing of uterine flushes in order to recover equine moralae. Equine Veterinary Journal Supplement 8 10-13.

Carnevale EM \& Ginther OJ 1992 Relationships of age to uterine function and reproductive efficiency in mares. Theriogenology 37 1101-1115.

Carnevale EM, Ramirez RJ, Squires EL, Alvarenga MA, Vanderwall DK \& McCue PM 2000 Factors affecting pregnancy rates and early embryonic death after equine embryo transfer. Theriogenology 54 965-979.

Clarke KE, Squires EL, McKinnon AO \& Seidel GE 1987 Viability of stored equine embryos. Journal of Animal Science 65 534-542.

Feo JC 1980 Contralateral implantation in mares mated during the post partum oestrus. Veterinary Record 106368 (Abstract).

Fleury JJ, Costa Neto JBF \& Alvarenga MA 1989 Results from an embryo transfer programme with Mangalarga mares in Brazil. Equine Veterinary Journal Supplement 8 73-74.

Fleury PDC, Alonso MA, Alvarenga MA \& Douglas RH 2004 Intervals to ovulation after treatment with oestradiol cypionate (ECP) or Biorelease Deslorelin (BRT-DES). In 6th International Symposium of Equine Embryo Transfer, Havemeyer Foundation Monograph Series No 14, p 89. Eds M Alvarenga \& J Wade. Newmarket, UK: R\&W Publications.

Gastal MO, Gastal EL, Kot K \& Ginther OJ 1996 Factors related to the time of fixation of the conceptus in mares. Theriogenology 46 1171-1180.

Gilbert CL, Lamming GE, Parkinson TJ, Flint APF \& Wathes DC 1989 Oxytocin influsion from day 10 after oestrus extends the luteal phase in nonpregnant cattle. Journal of Reproduction and Fertility 86 203-210.

Ginther OJ 1983a Fixation and orientation of the early equine conceptus. Theriogenology 19 613-623.

Ginther OJ $1983 b$ Mobility of the early equine conceptus. Theriogenology 19 603-611. 
Ginther OJ 1985 Dynamic physical interactions between the equine embryo and uterus. Equine Veterinary Journal Supplement 3 41-47.

Ginther OJ 1998 Equine pregnancy: physical interactions between the uterus and conceptus. Proceedings of the American Association of Equine Practitioners 44 73-105.

Goff AK, Pontbriand D \& Sirois J 1987 Oxytocin stimulation of plasma 15-keto-13,14-dihydro prostaglandin $\mathrm{F}_{2 \alpha}$ during the oestrous cycle and early pregnancy in the mare. Journal of Reproduction and Fertility Supplement 35 253-260.

Griffin PG \& Ginther OJ 1991 Uterine morphology and function in postpartum mares. Journal of Equine Veterinary Science 11 330-339.

Griffin PG \& Ginther OJ 1993 Effects of the embryo on uterine morphology and function in mares. Animal Reproduction Science 31 311-329.

Hinrichs K, Kenny RM \& Sharp DC 1989 Differences in protein content of uterine fluid related to duration of progesterone treatment in ovariectomised mares used as embryo transfer recipients. Equine Veterinary Journal Supplement 8 49-55.

Lambert RT, Ashworth CJ, Beattie L, Gebbie FE, Hutchinson JS, Kyle DJ \& Racey PA 2001 Temporal changes in reproductive hormones and conceptus-endometrial interactions during embryonic diapause and reactivation of the blastocyst in European roe deer (Capreolus capreolus). Reproduction 121 863-871.

Latshaw WK 1987 Embryonic membranes and placentation. In Veterinary Developmental Anatomy, pp 58-61. Ed. WK Latshaw. Toronto, Canada: BC Decker Inc.

Lawson RA, Parr RA \& Cahill LP 1983 Evidence for the maternal control of blastocyst growth after synchronous transfer of embryos to the uterus of the ewe. Journal of Reproduction and Fertility 67 477-483.

Ledgard AM, Lee RS \& Peterson AJ 2006 Expression of genes associated with allantois emergence in ovine and bovine conceptuses. Molecular Reproduction and Development 73 1084-1093.

Lopes FL, Desmarais JA \& Murphy BD 2004 Embryonic diapause and its regulation. Reproduction 128 669-678.

Losinno L, Aguilar JJ \& Lisa H 2001 Impact of multiple ovulations in a commercial equine embryo transfer programme. In Proceedings of the 5th International Symposium on Equine Embryo Transfer, Havemeyer Foundation Monograph Series 3, pp 81-83. Eds T Katila \& JF Wade. Newmarket, UK: R\&W Publications.

McCue PM \& Troedsson MHT 2003 Commercial embryo transfer in the United States. Pferdeheilkunde 19 689-692.

McDowell KJ, Sharp DC, Grubaugh W, Thatcher WW \& Wilcox CJ 1988 Restricted conceptus mobility results in failure of pregnancy maintenance in mares. Biology of Reproduction 39 340-348.

McKinnon AO \& Squires EL 1988 Morphological assessment of the equine embryo. Journal of the American Veterinary Medical Association 179 767-790.

Mead RA 1989 The physiology and evolution of delayed implantation in carnivores. In Carnivore Behaviour, Ecology and Evolution, vol 1, pp 437-464. Ed. JL Gittleman. Ithaca, NY: Cornell University Press.

Morris LHA \& Allen WR 2002 Reproductive efficiency of intensively managed Thoroughbred mares in Newmarket. Equine Veterinary Journal 34 51-60.

Oriol JG, Betteridge KJ, Clarke AJ \& Sharom FJ 1993a Mucin-like glycoproteins in the equine embryonic capsule. Molecular Reproduction and Development 34 255-265.

Oriol JG, Sharom FJ \& Betteridge KJ $1993 b$ Developmentally regulated changes in the glycoproteins of the equine embryonic capsule. Journal of Reproduction and Fertility 99 999-1003.

Peterson AJ, McMillan WH \& Thompson JG 2000 Various allantoic pathologies are associated with malformations of allantoic development of the IVP embryo. Proceedings of the 14th International Congress on Animal Reproduction, Stockholm, vol 5, p 158. Abstract.

Pool KF, Wilson JM, Webb GW, Kraemer DC, Potter GD \& Evans JW 1987 Exogenous hormone regimes to utilise successfully mares in dioestrus (days 2 to 14 after ovulation) as embryo transfer recipients. Journal of Reproduction and Fertility Supplement 35 429-432.
Pope WF 1988 Uterine asynchrony: a cause of embryonic loss. Biology of Reproduction 39 999-1003.

Rasweiler JJ \& Badwaik NK 1997 Delayed development in the short-tailed fruit bat (Carollia perspicillata). Journal of Reproduction and Fertility 109 7-20.

Rivera del Alamo MM, Reilas T, Kindahl H \& Katila T 2008 Mechanisms behind intrauterine device-induced luteal persistence in mares. Animal Reproduction Science 107 94-106.

Robinson TJ 1951 The control of fertility in sheep. Part II. The augmentation of fertility by gonadotrophin treatment of the ewe in the normal breeding season. Journal of Agricultural Science 41 6-63.

Sirois J, Betteridge KJ \& Goff AK 1987 PGF-2 $\alpha$ release, progesterone secretion and conceptus growth associated with successful and unsuccessful transcervical embryo transfer and reinsertion in the mare. Journal of Reproduction and Fertility Supplement 35 419-427.

Squires EL, Imel KL, Iuliano MF \& Shidler RK 1982 Factors affecting reproductive efficiency in an embryo transfer programme. Journal of Reproduction and Fertility Supplement 32 409-441.

Squires EL, Garcia RH \& Ginther OJ 1985 Factors affecting the success of equine embryo transfer. Equine Veterinary Journal Supplement $\mathbf{3}$ 920-925.

Stewart F, Gertstenberg C, Suire S \& Allen WR 1998 Immunlocalisation of a novel protein (P19) in the endometrium of fertile and subfertile mares. Journal of Reproduction and Fertility Supplement 56 593-599.

Stout TAE 2003 Selection and management of the embryo transfer donor mare. Pferdeheilkunde 19 685-688.

Stout TAE 2006 Equine embryo transfer: a review of developing potential. Equine Veterinary Journal 38 467-478.

Stout TAE, Lamming GE \& Allen WR 1999 Oxytocin administration prolongs luteal function in cyclic mares. Journal of Reproduction and Fertility 116 315-320.

Stout TAE, Lamming GE \& Allen WR 2000 The uterus as a source of oxytocin in the cyclic mare. Journal of Reproduction and Fertility Supplement 56 281-287.

Van Niekerk CH \& Allen WR 1975 Early embryonic development in the horse. Journal of Reproduction and Fertility Supplement 23 495-498.

Vogelsang SG, Bondioli KR \& Massey JM 1985 Commercial application of equine embryo transfer. Equine Veterinary Journal Supplement 3 89-91.

Wilmut I \& Sales DI 1981 Effect of an asynchronous environment on embryonic development in sheep. Journal of Reproduction and Fertility 61 179-184.

Wilmut I, Sales DI \& Ashworth CJ 1985 Physiological criteria for embryo mortality - is asynchrony between embryo and ewe a significant factor?. In The Genetics of Reproduction in Sheep, pp 275-289. Eds DB Lard \& D Robinson. London: Butterworths.

Wilmut I, Sales DI \& Ashworth CJ 1986 Maternal and embryonic factors associated with prenatal loss in mammals. Journal of Reproduction and Fertility 76 851-865.

Wilsher S \& Allen WR 2004 An improved method for nonsurgical embryo transfer in the mare. Equine Veterinary Education 16 39-44.

Wilsher S \& Allen WR 2009 Uterine influences on embryogenesis and early placentation in the horse revealed by transfer of day 10 embryos to day 3 recipient mares. Reproduction 137 583-593.

Zavy MT, Sharp DC, Bazer FW, Fazleabas A, Sessions F \& Roberts RM 1982 Identification of stage-specific and hormonally induced polypeptides in the uterine protein secretions of the mare during the oestrous cycle and pregnancy. Journal of Reproduction and Fertility 64 199-207.

Received 20 July 2009

First decision 11 September 2009

Revised manuscript received 12 November 2009

Accepted 30 November 2009 